\title{
Animals as Social Actors \\ Cases of equid resistance in the ancient Near East
}

\author{
Laerke Recht
}

\begin{abstract}
This paper examines the concept of animals as social actors in the ancient Near East through a case study of human-equid relations. In particular, examples where equids may be seen as expressing resistance, as depicted in the iconography of the third and second millennia BCE, are analysed. The first part of the paper discusses how animals have been perceived in scholarly debates in philosophy, archaeology and humananimal studies. It is argued that an acknowledgement of animals as social actors can improve our understanding of the human past, and the relation of humans to their broader environment. The second part of the paper presents three examples from the ancient Near East where equids may be interpreted as pushing back or resisting the boundaries placed by humans, resulting in a re-negotiation of the relationship.
\end{abstract}

\section{Introduction}

Animals have always permeated our lives. ${ }^{1}$ Although often ignored or unrealised, nonhuman animals feature in every part of day-to-day living: our language is saturated with animal imagery and references, all art forms contain them and our material culture is full of animals and products derived from them (for a long list of examples, see Bryant 2008). The web of interactions between humans and other animals means that the human perception of animals is highly varied and sometimes contradictory, from one people to another, from one person to another, and even within individuals. Animals may be seen as mere objects, relating to practicality, production and economics, as companions and pets, as adversaries, as equals and as status symbols. This is not only true of modern times, where their many presences and influences are perhaps more easily forgotten. In ancient times, nonhuman animals were at least as significant a part of human existence as they are today. They provided obvious products of subsistence in the form of meat, wool, skin, blood and milk, as well as transportation and traction/labour. Our earliest textual records concern themselves mostly with animals and animal products, and the earliest iconographic material from almost any part of the world depicts more animals than it does humans.

Correspondingly, human interactions with other animals constitute a complex map of relations, some more interactive than others - including killing, eating, abusing, skinning, milking, loving, respecting, honouring, adoring, worshipping, riding, leading, taming, setting free, feeding, breeding, training, playing, having intercourse, fighting, experimenting. The interaction occurring depends on factors such as time, place, cultural background, the kind of animal and the individual human being, and may appear contradictory. The same person may love and cherish their pet pig, yet one day send it to

\footnotetext{
${ }^{1}$ This paper is part of a Marie Skłodowska-Curie Fellowship entitled The Spirited Horse: Human-equid relations in the Bronze Age Near East (H2020, project TSH 741303); I am most grateful for the support of H2020 and Augusta McMahon. I also thank Ioanna Moutafi for graciously reading and commenting on a previous draft of the paper, and the editor and two anonymous reviewers for their suggestions, which helped me clarify the argument.
} 
the slaughter-house and later eat its meat. A loved companion dog may be beaten for some perceived insolence. In a way, these are merely extensions of the generally complex and contradictory nature of human behaviour, but they highlight the variety of ways in which we interact. Mapping these relations are therefore important elements in understanding human lifeways in the past.

In this paper, I begin from this view of animals as a constant and necessary presence in human existence. I outline the concept of animals as social actors and the implications that this might have for how we approach our study of the past and how humans negotiate relations with their surroundings. In the second part of the paper, I want to show how a view of animals as social actors might be detected in the material culture by presenting a case study consisting of three examples of human-equid interaction in the ancient Near East. The focus is on one specific type of encounter: that of animal resistance. This is only one of many kinds of interactions. ${ }^{2} \mathrm{I}$ have chosen resistance because it is one of the most powerfully expressed encounters, and a particularly vivid illustration of active animal engagement with humans. It is one where animals do not easily or willingly adapt to the boundaries set by humans, and thus may give rise to minor or major conflicts. For now, the emphasis is on the very existence and expression of such resistance; and the hope is that this will in turn open discussion about possible reasons behind it, along with the ancient human responses. The material under discussion is iconographic and largely comes from the third millennium BCE, with forays into the second millennium.

\section{Humans and other animals}

Philosophical discussions of animals go far back (Engel Jr. and Jenni 2010). In a remarkably subtle manner, Pythagoras allegedly believed that "The souls of animals called unreasoning are reasonable, not however with active reasoning powers, because of an imperfect mixture of the bodies and because they do not have the power of speech, as in the case of apes and dogs; for these have intelligence but not the power of speech" (Fairbanks 1898: 150-151). Mostly, however, the topic of animals is used as an opposite to define humans - that is, as a dichotomy, with 'human' on one (superior) side and 'animal' on the other (inferior) side, with animals seen as passive, amoral and irrational objects acting only on instinct. Hegel explicitly calls animals "anti-human" (Hegel 1998: 43) and Kant thought that humans are "through rank and dignity an entirely different being from things, such as irrational animals, with which one can do as one likes" (original emphasis, Kant 2010: 239; see also Kant 1997: 112. Cf. Derrida 2002: 399-400 on humans having taken the word 'animal' for themselves, to identify themselves). The most influential work of all is probably Descartes' comparison of animals with machines, clearly opposed to mind or soul as a human faculty (Descartes 1850: 98). These attitudes serve to marginalise animals and ignore the profound impact they have on every facet of human society. The associated rhetoric is also the kind that is in danger of being used for justifying abuse and cruelty towards animals (notice the difference outlined between anthropocentrism and speciesism in Boyd 2017).

In archaeology, research has tended to follow this general notion of animals as mostly of practical and economic value - that is, values that follow rational human thought. Studies

\footnotetext{
${ }^{2}$ A full discussion of all types of human-animal interactions is much beyond the scope of the current paper. More extensive research on this topic will appear in future publications of the TSH project.
} 
therefore focus on pastoralism, production, hunting/trapping and agriculture, although this has started to change. Archaeological finds are explained according to a logic that assumes rational use, usually based on economic factors. These studies are of course immensely valuable in contributing to our understanding of the ancient world. However, a more inclusive approach would provide a broader picture of the past, reflecting and acknowledging the variety of interactions and social players. In the last decades, there has been an increased awareness of and interest in these aspects in archaeological research, with some suggestions concerning how to begin to detect and interpret it in the archaeological record (see e.g. Ingold 1994, Arbuckle \& McCarty 2014, Harris \& Hamilakis 2014, Boyd 2017).

Much modern research in the field of human-animal studies also seeks to transcend the deep-rooted Cartesian model, especially in the fields of anthropology, sociology, animal rights groups and work focussing on ethics (DeMello 2010; Baker 2001; Walker 2008; Flynn 2008; Fudge 2002; Walker 2008; Calarco and Atterton 2004). In recent years, the awareness of this new work done on human-animal relations has opened the way for alternative interpretations, seeing animals as more than simple objects. Although various types of killing may be the most common interaction between humans and other animals (Animal Studies Group 2006), anthropological studies present us with a multitude of human approaches to other animals. Evans-Pritchard has famously shown how cattle are absolutely central to Nuer society, to the extent that members might be identified by reference to a specific ox, rather than the other way around (Evans-Pritchard 1956). Staying on the African continent, Malawians do not even have a category equivalent to 'animal' - the closest comparable division is one that involves entities that have life and those that do not. The things that have life, however, include not only animals, but also trees, spirit entities, souls of the dead, edible mushrooms, rain and soil (Morris 2000: 140-141). Rather than have a broad category of 'animals', they have categories such as 'edible quadruped', 'birds', 'intestinal worms', 'fish, edible crustaceans, snakes' and 'useless organisms' (Morris 2000: 144). These reflect the Malawi way of life and present a radically different perception of the world and emphasise the fact that not all animals are the same. In Amerindian thought, animals are seen as persons - or more accurately, some types of animals are understood by humans as conceiving themselves as persons:

[Animals] perceive themselves as (or become) anthropomorphic beings when they are in their own houses or villages and they experience their own habits and characteristics in the form of culture - they see their food as human food (jaguars see blood as manioc beer, vultures see the maggots in rotting meat as grilled fish, etc.), they see their bodily attributes (fur, feathers, claws, beaks etc.) as body decorations or cultural instruments, they see their social system as organized in the same way as human institutions are (with chiefs, shamans, ceremonies, exogamous moieties etc.) (Viveiros de Castro 1998: 470).

This is a wonderful instance of animals being seen as full-blown social actors within their own society, with human concerns and attitudes (although admittedly within an inescapably human cognitive framework). In the modern Western world, we do not tend to conceptually integrate animals into our everyday lives in the same degree, but it is precisely these intriguing cases that transcend our usual perception of animals as passive objects that I am interested in.

\section{The dangers of 'animal'}


Two important caveats should be noted. Firstly, the word 'animals' of course includes humans. However, in this paper, it refers specifically to nonhuman animals. I am fully aware that this does nothing to help the issue of the human-nonhuman animal dichotomy described above, but consider it preferable to the repeated use of the cumbersome alternative since the meaning is hopefully clear from the context of the discussion here.

Secondly, the term 'animal' (or 'the animal' or 'the Animal') is not a simple or unproblematic word in what it encompasses. As Derrida would have it,

Confined within this catch-all concept $\ldots$ are all the living things that man does not recognize as his fellows, his neighbors, or his brothers. And that is so in spite of the infinite space that separates the lizard from the dog, the protozoon from the dolphin, the shark from the lamb, the parrot from the chimpanzee, the camel from the eagle, the squirrel from the tiger or the elephant from the cat, the ant from the silkworm or the hedgehog from the echidna. (Derrida 2002: 402).

It lumps together a large amount of hugely diverse life-forms into a single category, which robs animals of individuality and uniqueness when in fact not just species but each individual animal does possess specific characteristics, what we in a human would call their 'personality'. This general category can thus easily become a tool of the dichotomous rhetoric that places humans opposite and superior to 'animals' (consider for a moment the implications of the 'animal' equivalent of 'personality'; 'animality'). The abolishment of the word is unlikely to change this conceptual gap, nor can (or should) its place as a significant category in modern Western thought so easily be abolished. Hence, I am using it here, but would ask readers to keep in mind the immense diversity that it always entails and refers to.

\section{What is a 'social actor'?}

The concept of 'social action' is most commonly used in sociology and anthropology, but has also found its way into archaeology through various agency theories (Dornan 2002). It is variously defined as

- "a type of behavior that is oriented to the behavior of another actor, and to which the actor attaches meaning" (Swedberg and Agevall 2005: 246, "social action")

- "Behavior which has meaning to the individual, that is, behavior which he directs toward a goal"; "Action oriented to or influenced by another person or persons" (Theodorson and Theodorson 1970: 4, "action" and "action, social")

- "Action is social when the actor behaves in such a manner that his action is intended to influence the actions of one or more other persons" (Mitchell 2006: 2, "action; social action")

- "the capacity of human beings to affect their own life chances and those of others and to play a role in the formation of the social realities in which they participate" (Barfield 1997: 4, "agency or human agency") 
- "the capacity that all individual humans (or agents) have to actively shape and transform their world, with a degree of self-consciousness or awareness that sets them apart from other species" (Gardner 2009: 95)

Social action is often placed in opposition to structure. Structure refers to the theory that behaviour is governed by the social systems in which a person - or animal - may find themselves, giving little credence to independent choice and action (Johnson 2000: 6). I am not here dismissing the forces of structures in determining behaviour - in fact, a blend of the two positions provide the best explanation, making them interdependent (Giddens 1979: 255), or as Gardner describes it "companions" (Gardner 2009: 95). This being said, I intend to shift the focus to individual, nonhuman animal agents, which may be restrained and reside within social structures, but nevertheless have and act upon individual autonomy.

As definitions go, the above are in remarkable agreement, all emphasising the ability or perceived ability to shape one's surroundings and that the action should be interactive, i.e. social. On top of this, there is a reference to the state of mind of the agent - 'attaching meaning', 'directing behaviour', 'intending', 'self-consciousness' and 'awareness' all suggest deliberation behind any actions performed. This element is probably the reason why social action is usually linked to humans - and explicitly so in Gardner's article (Gardner 2009). However, the issue is murky. Are animals capable of self-consciousness? Various tests have been devised to answer this question, including the so-called 'Mirror Test' $^{3}$, which has been used with some advantage on chimpanzees and orangutans (Gallup 2005). The debate is a very heated one, with discussions not only on species close to humans - see for example contributions in Parker et al. 2006 and Beckoff et al. 2002. Certainly, animals navigate social structures in ways similar to humans. As Mlekuž notes in reference to sheep, they are "skilled social players actively negotiating and renegotiating society and their positions within it" (2013: 152).

Self-consciousness is at the extreme of the spectre of defining social action - a 'softer' version, which does involve a sense of deliberation, but not necessarily to the extent that it would constitute self-consciousness, may be more reasonable. This means a more inclusive approach, ensuring that actions performed without self-consciousness by agents with the capacity for self-consciousness are included, as well as actions performed by humans with limited or no capacity for self-consciousness (for example young children and people born with limited mental capacity). A social actor is thus an agent that deliberately (and more or less consciously) seeks to influence their world. They actively engage with other agents and their surroundings.

Animals are thus seen as subjects, having motives and objectives, and with the ability to influence the world around them, including other agents such as humans. This influence can take many forms. Hribal, for example, writes about the many ways in which animals actively resist human interaction, perhaps the most explicit manner of attempting to shape their own worlds (Hribal 2007). The concept of resistance is a central feature of much theoretical literature on inequality and power relations (Paynter \& McGuire 1991; Gailey

\footnotetext{
${ }^{3}$ The basic idea is to determine whether an animal recognises itself in a mirror. This is done by applying an odourless dye to a part of the animal's body that it would not be able to see without a mirror, then introducing (or reintroducing) the mirror to see if the animal directs attention to the area dyed, thereby proving that it links the mirror image to its own self (Gallup 1970). Since the test is purely based on visual input, an animal's failure to recognise itself is not proof that it lacks self-awareness, but if recognition occurs it is an indicator that the animal is capable of some sense of self. Interestingly, studies have also shown that at least some animals, including horses and sheep, are able to recognise individual human faces and even emotional expressions (Kendrick et al. 2001, Proops et al. 2018).
} 
1987, cf. Saitta 1994). It is often placed as a dichotomous counterpart to domination, with associations with organised or class action against an oppressive elite. 'Resistance' becomes almost synonymous with oppression and miserable conditions on one part, and ill-intended power-plays on the other. That is not how resistance is used in this paper: equids were not planning an organised rebellion against their human oppressors. We might see something closer to Paynter and McGuire's idea of "everyday resistance", as in small everyday acts, which are in fact often invisible in the archaeological record (1991: 12-13). This is a useful concept, but it maintains the dichotomous and strongly antagonistic meaning.

While resistance can be an antagonistic response to violence or abuse, the relationship between human and animal is more complex and varied than that. Partly as a response to Ingold's characterisation of domestication as domination (1994), Armstrong Oma refers to the relationship as a social contract (2010), albeit not a symmetrical one. In the examples discussed here, what we may detect are interactions of continuous negotiation between human and equid - also sometimes called 'becoming with' (Haraway 2008). Both are forced to rethink their behaviour based on the actions of the other; this can, but does not have to entail a desire to actually leave or even substantially change the relationship. Resistance means actively pushing back, acting against the limits set (by humans) in a particular encounter. It expresses a desire not to engage within the set parameters, along with attempts to alter those parameters, to a small or greater extent. It should be stressed that this is only one way among many others that animal agency can be expressed. ${ }^{4}$ But precisely because resistance is such a forceful assertion of agency, it serves as a good starting point for demonstrating one example of role of animals as social actors.

\section{Equids in the Bronze Age Near East}

Partly due to the diversity of animal agency, which it would be impossible to give due attention in a short study of this nature, I have chosen to focus on only one type of animal as a case study: equids. The other reason I have chosen this one animal is that the iconographic material of the ancient Near East pertaining to equids lends itself particularly well to suggesting a variety of roles and perceptions. I would emphasise again that I am not here concerned so much with how humans have used (and abused) animals as passive objects, or with how this is reflected in the iconography. Rather, I want to nudge the material to see how it might reveal something about the active influences that equids had on the people of the ancient Near East. That is, equids are seen as social actors in the sense that they actively and deliberately react to human contact, thereby being part of the forces that shape that relationship.

Representational material of any kind exists within a complex set of ideological, cultural and historical parameters, coupled with artistic license and tradition. Interpreting it involves embodied and individual evaluation. The pieces discussed here are certainly not direct representations of ancient realities. ${ }^{5}$ Instead, they are demonstrations of the knowledge of certain concepts. The depiction of the features discussed implies an

\footnotetext{
4 As Dornan notes, agency is at times equated with resistance (2002: 318), which is an unfortunate and oversimplified view of the many different ways in which both humans and other animals interact with their environment.

${ }^{5}$ If nothing else, this is clear from a study of the details of some of the objects: for example, the paces of the equids do not reflect actual equid movement - a good example of artistic convention.
} 
awareness of the existence of such features, whether they relate to tack or equid behaviour and gestures. Crucially, the behaviour depicted closely corresponds to how equids use gesture and body language, making it much more likely that this was actually observed and not conjured from the imagination of the craftspersons. Further, any meaning attached to these features comes from knowledge of this behaviour. Take the example of horses shown with open mouths (and perhaps a bit). The craftsperson may intend to convey the idea of a 'spirited' horse, eager to go: the meaning of this is lost without knowing that this is how a horse might react to the bit.

\section{Equids pushing back}

I want to suggest three ways in which equids can be seen to resist or 'push back' in their encounter with humans in the ancient Near East. These do not necessarily imply a complete rejection of the relationship, but they do illustrate degrees of animals carrying out actions in order to influence their situation or the condition they find themselves in.

The first example comes from a certain type of equid terracotta figurine belonging to the second half of the third millennium BCE, with a few early second millennium examples, and mostly found in the Khabur region of Syria. The type seems limited to a few sites: Tell Mozan/Urkesh (Hauser 2007; Bianchi \& Wissing 2009), Tell Brak/Nagar (Oates et al. 2001), and Tell Arbid (Makowski 2014; 2015). ${ }^{6}$ These figurines depict an equid which is clearly marked as male due to the presence of male genitals (figs. 1-3). Significantly, not only are the genitals marked, they are also covered by some kind of strap (most likely made of leather). Exactly how the strap stays on is not clear, but it may be attached to a more complex system of tack that extends up over the back of the equid, with additional straps to the front and the back (fig. 2). Whatever the means, it must have caused some difficulty keeping the device in place (not to mention challenging to attach in the first place), and very likely a source of discomfort for the equid.

The strap is a means of controlling the equid. It has persuasively been interpreted as reflecting breeding practices (e.g. Hauser 2007: 373, Makowski 2014: 262). Precisely when the different species of equids were domesticated in the Near East is a matter of some debate, which I will not endeavour to cover here (for a detailed study, see Zarins 2014). Certainly by the second half of the third millennium BCE, we have good evidence that selective breeding of equids took place, and that certain cities were famous for their equids. It is probably no coincidence that ancient Nagar was one of them (Eidem et al. 2001: 101; Oates 2001: 286). This would have involved mostly domesticated equids, but it is possible that wild individuals, in particular onagers, were used to supplement the pedigree. In fact it seems that the most prestigious equid at this point was the kunga perhaps a donkey-onager hybrid (Postgate 1986). This would require capturing and managing wild onagers and persuading them to breed with the domestic donkeys.

Whatever the details of the mechanisms of the breeding programmes, the figurines reveal that at least the stallions needed strong measures of control. ${ }^{7}$ These measures would only be necessary because the equids were resisting the human intervention and not immediately fitting into the human scheme of things. In other words, the equid

\footnotetext{
${ }^{6}$ One example is also reported from Tepe Gawra, dating to the Akkadian period (Speiser 1935: 69-70, pl. XXXIVc.5). 7 The terracotta figurines are rarely marked as female, only a few examples are recorded from Tell Mozan (Hauser 2007: 374), and Tell Arbid (Makowski 2015: 629).
} 
behaviour forced humans to adapt and come up with alternative solutions. In this particular case, the solution (or at least one solution - we do not know if others were tested) appears both impractical and unpleasant, although the former is mostly a matter of conjecture.

The second example is best expressed in half a dozen inlays, also dated to the second half of the third millennium BCE, from the site of ancient Mari on the Euphrates in eastern Syria (Margueron 2004: 291, 293, figs. 279a, 282.14, 282.16. 282.17, 282.18; Parrot 1967: pls. LXV nos. 2467, 2468, 3072). Unfortunately, none of the inlays are complete, but the fragments that do survive reveal astonishing details of equids pulling wheeled vehicles. They depict teams of equids, usually in fours (figs. 4-5). In the twodimensional media, equids are shown in profile, and to mark the number of animals, further outlines are simply shown along the lines of the front one. In contrast, a different perspective is used for humans, who are nearly always shown as separate complete individuals. The method used for the equids makes it clear that they are a team - on fig. 4, clearly a team of four arranged shoulder to shoulder (in modern-day carriage driving, this would be a highly unusual arrangement; pairs of two would be preferable). The inlays clearly show the components of the bridle, with a simple headstall and noseband. The equids were controlled with lip rings, which is probably something that was adapted from their use with cattle (Littauer \& Crouwel 1979: 30-31). Bits do not yet appear to have been widely known at this point.

What I want to draw attention to here is what may at first appear to be a very broad noseband (fig. 4). Actually, it is so low and partly covering the nostrils that is it more likely a muzzle, or at least functioned as such. ${ }^{8}$ This becomes clearer in some instances where it does go all the way to the bottom of the lips of the equids (fig. 5). Along with the inlays, a number of equid terracotta figurines illustrate the same idea, where we can note patches of clay placed over the mouth of the animal (figs. 6-7).

Different models seem to have been available, or perhaps experimented with: a broad band basically extending downwards from the noseband, to the nostrils or partly covering the nostrils (fig. 4); a patch covering only the lower part of the mouth, leaving the upper part (with nostrils) entirely free (fig. 5); and a patch or strap going from the front of the noseband over the mouth and to the back of the noseband, also leaving the nostrils free (figs. 6-7). The latter is only found on the figurines, but would also be difficult to render in the two-dimensional medium where only profiles were used. The first type is the only one which seems to be designed to impede breathing, and may therefore have the further function of subduing animals who are particularly temperamental.

The main idea of the muzzle is to keep the mouths of the equids tight and prevent them from being able to bite. This may be protection for their human grooms and trainers, but is just as likely to be to avoid the equids bickering and biting each other. Such bickering might be particularly bad when dealing with a team of four stallions, as on the Standard of Ur (fig. 8), but can equally well occur with mares or even geldings. Unfortunately, the bodies of the equids are not preserved on the inlays from Mari that show the muzzles, and the same applies to the terracotta figurines, so it is not at present possible to determine if there is a direct correlation between the use of muzzles and the sex of the equids.

${ }^{8}$ See also Littauer 1969 for a discussion of the effect of low nosebands. 
Equids can bite for a number of reasons, not all of which are related to aggression. The point is that the action was deemed undesirable by humans and therefore limiting measures were applied. To what extent the muzzle was an effective response to this type of pushing back is not known. It does not appear to have continued into the second millennium BCE, which may be related to other changes occurring in human-equid relations at that time (for example, the use of the bit and two reins and the increasing popularity of horses for pulling wheeled vehicles).

The third form of pushing back is also the most tentative as it depends on the degree to which one believes ancient craftspersons to reflect reality in their work, and to be able to reflect the 'body language' of animals. A careful look at the many depictions of equids in front of wheeled vehicles in glyptics and on plaques or inlays and terracotta figurines wearing bridles reveals that in many cases, tension is marked in the positioning of the neck and head. This tension is almost certainly a reaction to the bridle elements (nose/lip ring, noseband and/or bit) and them being pulled by the driver (or potentially in some cases, a rider).

The tension can be detected by noticing the angle of the neck to the body and the ground, and the angle of the head both in relation to the neck and in the relation to the ground. Normally, if an equid is not grazing, it will hold its head at a roughly 30-40 degree angle to the ground and its body - horses tend to have a higher set neck than donkeys, especially some modern breeds. The head would then be roughly 90 degrees in relation to the neck (fig. 9). In the gallop, the neck may come up and down a bit, following the rhythm of the movement, as the animal uses the neck for balance.

In many of the depictions, we see the neck placed at almost 90 degree angles to the body of the equid. This is apparent in some of the third millennium plaques and inlays already presented. The so-called Standard of Ur may serve as an example by comparing the equids on each of the long sides. On the 'Peace' side (fig. 8a), the team of four equids are walking; they are being led by a person walking in front of them, and are not pulling a vehicle. Their necks are set slightly higher that might be expected (at a roughly 50 degree angle), but not so extreme as to express strong opposition. On the 'War' side (fig. 8b), the teams of equids in the lowest register display a different attitude: their necks are very high, close to the 90 degree angle. The discomfort is even more evident on a plaque from Nippur (fig. 10), where the bulging of the front of the neck and the open mouth emphasise the tension. The open mouth is a common reaction to the bit in equids, but here it instead reveals a reaction to the pressure of the pull of the lip ring and/or noseband. Similar features can be detected in some of the terracotta figurines (see e.g. Meyer \& Pruß 1994: 127, no. 199, fig, 38, pl. 17; Mallowan 1937: 130, fig. 10.24; Strommenger \& Miglus 2010: 64, pl. 61.2).

The behaviour seems to have been observed throughout the third and second millennia BCE, but it again more clearly appears in the Late Bronze Age on objects with some degree of inspiration from Egyptian art (and from sites geographically closer to Egypt). Egyptian depictions of horses and chariots often show the tension as rather extreme, with high bulging necks, head curled close to the neck, and the tension continuing all the way down the spine (fig. 11). Similar compositions appear on gold vessels found at Ugarit (fig. 12, and Louvre AO 17208). At this point in time, the equids are generally horses, and the bit has become more commonly known. The reaction in the neck is therefore related to the pulling of the bit, with the open mouth emphasising this.

What we see in these examples is equids attempting to resist the pull of their human drivers. In these cases, the resistance is either through pushing on the bit or the 
noseband with the gums or front of the head, or through avoidance, pushing the head backwards. The variety and development in bridles and bridle elements (including bits) illustrate that this pushing resulted in a negotiation between human and equid, with humans trying to find the most efficient way of persuading equids to follow and understand instructions (a negotiation that is in many ways ongoing today). As we have seen with the noseband, the effect on the equid depends very much on the type of bridle and bit. Experimentation with this can also be seen when the metal bit becomes more common, as discussed in detail by Littauer (1969). For example, studs on the inside of the bit rings/guards (what Littauer calls cheekpieces) may provoke a more immediate response, and riders today will use a combination of specific bridle and bit types to suit the temperament of each horse.

I mentioned that the interpretation of this 'body language' is tentative, so what might be the alternative(s)? Many aspects of Near Eastern art are very standardised, and certain features remain the same from the beginning of the third millennium through the first millennium BCE. For example, the teams of equids in front of chariots and other wheeled vehicles are always shown as overlapping, not individually rendered animals. The way animals are shown as walking or galloping also remains quite constant (and this applies to other animals as well). The high neck could thus be put down to artistic convention. However, far from all equids - or indeed other animals - are shown with the high, tensioned neck. In fact, some Old Babylonian images of ridden equids show a relaxed neck and head (e.g. Legrain 1930: 32, pl. LII no. 277). These are closely associated with a loose rope that is not being pulled hard, at least in the moment captured, and this may be a clue as to why the equids appear more relaxed.

The images from the Late Bronze Age suggest a more complex situation. Since they are all of horses, we are dealing with a neck that may be set higher naturally. Depicting the head and neck as raised so high seems indeed to be an Egyptian convention. This convention does reflect actual behaviour in that it also frequently shows the open mouth reaction to the bit, but it may be more than that. It may be a way precisely to make a clear distinction between horses and other equids; ${ }^{9}$ it is also possible that the high neck was associated with particularly prestigious horses (even a certain breed, or coming from a specific 'stable'). Beside the element of resistance, whatever the initial reasoning behind the convention, it appears to have trickled into some of the objects created in the Levant, and may also have something to do with the way horses are consistently shown with exaggerated high necks in Mycenaean art.

These three examples all concern equid reaction to tack invented by humans to manage equid behaviour. In a sense, it could be argued that all tack is a reflection of equids pushing back, and to a degree this would indeed be the case. It is at least the case to the extent that all tack per definition involves a human-equid relationship, and all tack is a part of the negotiation of that relationship. I have here chosen to emphasise elements that reveal a stronger sense of the equid actually resisting, and that have forced a change in human behaviour. For example, genital straps would not have been applied the minute humans first caught or domesticated equids, or decided to carry out selective breeding. They are a human solution to equids being equids. Likewise, bridles, lip/nose rings, bits and muzzles are responses to equids pushing back and not immediately fitting within the restrictions set by humans. To what extent the equid resistance was successful is a

\footnotetext{
${ }^{9}$ This is done in other ways as well, especially when the horse was fairly new and the artist needed to be explicit that a different animal was depicted (Lonneke Delpeut, pers. comm., 30 Nov 2018).
} 
question for another time, but what is clear is that it did result in re-negotiations of the relationship, even if the relationship is unlikely to have been a symmetrical one.

\section{Conclusion}

My aim with this paper is two-fold: 1) to provide an overview of the concept of animals as social actors, and 2) to offer examples of how animal agency might be recognised in the material culture, in this instance primarily from the third millennium BCE Near East. Animal actors are seen as having the capacity to actively attempt to shape their lives through interaction with their surroundings, in particular in their relations to humans. The cases demonstrating equids pushing back and thus influencing the relationship discussed here are those of breeding controls in the form of genital straps on stallions, the use of muzzles to prevent biting, and the occurrence of tension expressed in the 'body language' of depicted equids. In order to offer a clearly delimited case study, I have focussed on iconographic evidence for these examples, but other examples could be drawn from examining faunal remains, archaeological contexts associated with equids, and textual references to equid management and behaviour. These may also reveal other types of equid social action.

The examples are pieces in the huge jigsaw puzzle that is the past. They are a kind of 'close up' and do not constitute a grand narrative on their own. But they are - or should be - part of the grand narrative of, say, the Bronze Age of the Near East. The small changes that equid resistance and continued social negotiations may have caused are important for individual or specific encounters, but they also have greater and longterm implications. A resistance to the lip ring and its inefficiency in communicating direction may have lead to experimentation with other forms of tack, including the bit. Ultimately, and whatever their origin, these new devices heralded great changes in warfare; understanding equids as social actors is thus revealing of even large and longterm processes.

Archaeological studies tend to be deeply anthropocentric. There is one excellent reason for this: archaeology without humans would no longer be archaeology. However, abandoning or moving away from a strong anthropocentric approach does not need to entail abandoning humans. If it instead is a de-centering that places humans in their environment - with every micro-relationship that that implies - we have a real opportunity to greatly enrich our understanding and knowledge of all aspects of the past and the archaeological record. This is not a call for a flat ontology in the sense that all things and beings have equal value - whether or not they do, they clearly have not been perceived or treated as such. These asymmetries or unequal relations are part of the understanding of humans and how we negotiate, assert or relinquish our place within each relationship. The specific study of animals as social actors is then part of the understanding of how animals actively negotiate, assert or resist their place in relations to humans, and how this affects human behaviour and lifeways. 
Laerke Recht, Marie Skłodowska-Curie Fellow, McDonald Institute for Archaeological Research, University of Cambridge.1r459@cam.ac.uk

\section{References}

Animal Studies Group. 2006. Killing Animals. Urbana \& Chicago: University of Illinois Press.

Arbuckle, Benjamin S., and Sue Ann McCarty, eds. 2014. Animals and Inequality in the Ancient World. Boulder: University Press of Colorado.

Armstrong Oma, Kristin. 2010. "Between Trust and Domination: Social Contracts between Humans and Animals." World Archaeology 42 (2): 175-187.

Baker, Steve. 2001. Picturing the Beast: Animals, Identity, and Representation. Urbana: University of Illinois Press.

Barfield, Thomas, ed. 1997. The Dictionary of Anthropology. Oxford: Blackwell.

Bekoff, Marc, Colin Allen, and Gordon M. Burghardt, eds. 2002. The Cognitive Animal: Empirical and Theoretical Perspectives on Animal Cognition. Cambridge, Mass.: MIT Press.

Bentley, R. Alexander, Christopher Chippindale, and Herbert D. G. Maschner, eds. 2009. Handbook of Archaeological Theories. Lanham, MD: Rowman \& Littlefield.

Bianchi, A., and Anne Wissing. 2009. Ausgrabungen 1998-2001 in Der Zentralen Oberstadt von Tall Mozan/Urkes: Die Kleinfunde. Wiesbaden: Harrassowitz.

Boyd, Brian. 2017. "Archaeology and Human-Animal Relations: Thinking Through Anthropocentrism.” Annual Review of Anthropology 46 (1): 299-316.

Bryant, Clifton D. 2008. “The Zoological Connection: Animal-Related Human Behavior.” In Social Creatures, edited by Clifton P. Flynn, 7-21.

Calarco, Matthew, and Peter Atterton, eds. 2004. Animal Philosophy: Essential Readings in Continental Thought. London \& New York: Continuum.

DeMello, Margo, ed. 2010. Teaching the Animal: Human-Animal Studies across the Disciplines. Brooklyn: Lantern Books.

Derrida, Jacques. 2002. "The Animal That Therefore I Am (More to Follow)." Critical Inquiry 28 (2): 369-418.

Descartes, Rene. 1850. [1637] Discourse on the Method of Rightly Conducting the Reason, and Seeking the Truth in the Sciences. Translated by John Veltch. Edinburgh: Sutherland \& Knox.

Dornan, Jennifer L. 2002. “Agency and Archaeology: Past, Present, and Future

Directions." Journal of Archaeological Method and Theory 9 (4): 303-329. 
Eidem, Jesper, Irving Finkel, and Marco Bonechi. 2001. "The Third-Millennium Inscriptions." In Excavations at Tell Brak. Vol. 2: Nagar in the Third Millennium BC, by David Oates, Joan Oates, and Helen McDonald, 99-120. London: British School of Archaeology in Iraq.

Engel Jr., Mylan, and Kathie Jenni. 2010. "Examined Lives: Teaching Human-Animal Studies in Philosophy." In Teaching the Animal, edited by Margo DeMello, 60-102.

Fairbanks, Arthur. 1898. The First Philosophers of Greece: An Edition and Translation of the Remaining Fragments of the Pre-Sokratic Philosophers, Together with a Translation of the More Important Accounts of Their Opinions Contained in the Early Epitomes of Their Works. London: Kegan Paul.

Flynn, Clifton P., ed. 2008. Social Creatures: A Human and Animal Studies Reader. New York: Lantern Books.

Fudge, Erica. 2002. Animal. London: Reaktion Books.

Gailey, Christine W. 1987. “Culture Wars: Resistance to State Formation.” In Power Relations and State Formation, edited by T.C. Patterson and C.W. Gailey, 35-56.

Washington, D.C.: American Anthropological Association.

Gallup Jr., Gordon G. 1970. “Chimpanzees: Self-Recognition.” Science 167 (3914): 86-87.

- 1982. "Self-awareness and the Emergence of Mind in Primates." American Journal of Primatology 2 (3): 237-48.

Gardner, Andrew. 2009. "Agency.” In Handbook of Archaeological Theories, edited by R. Alexander Bentley, Herbert D. G. Maschner, and Christopher Chippindale, 95-108.

Giddens, Anthony. 1979. Central Problems in Social Theory: Action, Structure, and Contradiction in Social Analysis. London: Macmillan.

Haraway, Donna Jeanna. 2008. When Species Meet. Minneapolis \& London: University of Minnesota Press.

Harris, Kerry and Yannis Hamilakis. 2014. "Beyond the Wild, the Feral, and the Domestic: Lessons from Prehistoric Crete". In Routledge Handbook of Human-Animal Relations, edited by G. Marvin and S. McHugh, 93-98. Abingdon \& New York: Routledge.

Hauser, Rick. 2007. Reading Figurines: Animal Representations in Terra Cotta from Royal Building AK at Urkesh (Tell Mozan). Urkesh/Mozan Studies 5. Malibu: Undena Publications.

Hegel, Georg Wilhelm Friedrich. 1998. Phenomenology of Spirit. Translated by A.V. Miller. Delhi: Motilal Banarsidass.

Hribal, Jason. 2007. "Animals, Agency, and Class: Writing the History of Animals from Below.” Human Ecology Review 14 (1): 101-12. 
Ingold, Tim. 1994. "From Trust to Domination: An Alternative History of HumanAnimal Relations." In Animals and Human Society: Changing Perspectives, edited by A. Manning and J. Serpell, 1-22. London \& New York: Routledge.

Johnson, Allan G. 2000. The Blackwell Dictionary of Sociology: A User's Guide to Sociological Language. 2nd ed. Malden, Mass.: Blackwell.

Kant, Immanuel. 1997. Lectures on Ethics. Translated by Peter Heath. Cambridge: Cambridge University Press.

- 2010. "Anthropology from a Pragmatic Point of View”. In Anthropology, History, and Education, edited and translated by Robert B. Louden, 227-429. Cambridge:

Cambridge University Press. [Original 1798. Akademie der Wissenschaften 7]

Kendrick, Keith M., Ana P. da Costa, Andrea E. Leigh, Michael R. Hinton, and Jon W. Peirce. 2001. "Sheep Don't Forget a Face.” Nature 414 (6860): 165-166.

Mlekuž, Dimitrij. 2013. “The Birth of the Herd.” Society \& Animals 21 (2): 150-161.

Legrain, Leon. 1930. Terra-Cottas from Nippur. Philadelphia: University of Pennsylvania Press.

Littauer, Mary Aiken. 1969. "Bits and Pieces." Antiquity 43 (172): 289-300.

Littauer, Mary Aiken, and Joost H. Crouwel. 1979. Wheeled Vehicles and Ridden Animals in the Ancient Near East. Leiden/Köln: Brill.

Makowski, M. 2014. “Terracotta Equid Figurines from Tell Arbid: New Evidence on Equids, Their Equipment and Exploration in North Mesopotamia during Third and First Half of Second Millennium BC." Études et Travaux 27: 257-78.

—. 2015. "Zoomorphic Clay Figurines from Tell Arbid. Preliminary Report." Polish Archaeology in the Mediterranean 24 (1): 627-56.

Mallowan, M.E.L. 1937. "The Excavations at Tall Chagar Bazar and an Archaeological Survey of the Habur Region. Second Campaign, 1936." Iraq 4 (2): 91-177.

Margueron, Jean. 2004. Mari, Métropole de l'Euphrate Au IIIe et Au Début Du IIe Millénaire Av. J.-C. Paris: Picard.

Meyer, Jan-Waalke, and Alexander Pruss. 1994. Ausgrabungen in Halawa 2: Die Kleinfunde von Tell Halawa A. Saarbrücken: Saarbrücker Druckerei und Verlag.

Mitchell, Geoffrey Duncan, ed. 2006. A New Dictionary of the Social Sciences. 2nd ed. New Brunswick, N.J.: Transaction Publishers.

Morris, Brian. 2000. The Power of Animals: An Ethnography. Oxford \& New York: Berg.

Oates, David, Joan Oates, and Helen McDonald. 2001. Excavations at Tell Brak. Vol. 2: Nagar in the Third Millennium BC. London: British School of Archaeology in Iraq. 
Oates, Joan. 2001. "Equid Figurines and 'chariot' Models." In Excavations at Tell Brak. Vol. 2: Nagar in the Third Millennium BC, by David Oates, Joan Oates, and Helen MacDonald, 279-93. London: British School of Archaeology in Iraq.

Parker, Sue Taylor, Robert W. Mitchell, and Maria L. Boccia, eds. 2006. Self-Awareness in Animals and Humans: Developmental Perspectives. Cambridge: Cambridge University Press.

Parrot, André. 1956. Mission archéologique de Mari. Vol.1: Le temple d'Ishtar. Paris: P. Geuthner. 1967. Mission archéologique de Mari. Vol.3: Les temples d'Ishtarat et de Ninni-Zaza. Paris: P. Geuthner.

Paynter, Robert and Randall H. McGuire. 1991. "The Archaeology of Inequality: Material Culture, Domination, and Resistance." In The Archaeology of Inequality, edited by R.H. McGuire and R. Paynter, 1-27. Oxford: Blackwell.

Postgate, J. Nicholas. 1986. "The Equids of Sumer, Again.” In Equids in the Ancient World, edited by Richard H. Meadow and Hans-Peter Uerpmann, 194-204. Wiesbaden: Ludwig Reichert.

Proops, Leanne, Kate Grounds, Amy Victoria Smith, and Karen McComb. 2018. "Animals Remember Previous Facial Expressions That Specific Humans Have Exhibited.” Current Biology 28 (9): 1428-1432.

Saitta, Dean J. 1994. “Agency, Class, and Archaeological Interpretation.” Journal of Anthropological Archaeology 13 (3): 201-227.

Schaeffer, C.F.A. 1949. Ugaritica II. Mission de Ras Shamra V. Paris: P. Geuthner.

Speiser, E. A. 1935. Excavations at Tepe Gawra. Vol. I: Levels I-VIII. Philadelphia: University of Pennsylvania Press.

Strommenger, Eva, and Peter A. Miglus. 2010. Tall Bïa/Tuttul V: Altorientalische Kleinfunde. Wiesbaden: Harrassowitz.

Theodorson, George A., and Achilles G. Theodorson. 1970. A Modern Dictionary of Sociology. London: Methuen.

Walker, William H. 2008. "Practice and Nonhuman Social Actors: The Afterlife Histories of Witches and Dogs in the American Southwest." In Memory Work, edited by Barbara J. Mills and William H. Walker, 137-57. Santa Fe: School for Advanced Research Press.

Zarins, J. 2014. The Domestication of Equidae in Third-Millennium BCE Mesopotamia. Bethesda: CDL Press.

Laerke Recht is currently working on a project entitled The Spirited Horse: Human-animal relations in the Bronze Age Near East. Beside human-animal relations in archaeology, her 
research interests include religion, gender relations, exchange networks and ceramics in the Aegean and Near East.

Related publications:

2018. “'Asses were buried with him': Equids as markers of sacred space in the third and second millennia BC in the Eastern Mediterranean", in Louis Nebelsick et al. (eds.), Sacred space: Contributions to the archaeology of belief, 65-94.

2018. "Horse figurines from Hala Sultan Tekke", Opuscula 11

2014. "Transformers Energise! Aegean Bronze Age rhyta in moments of transformation", 35-51 in Clare Rowan and Annabel Bokern (eds). Embodying Value. BAR. 
Animals as Social Actors - List of figures

Fig. 1. Terracotta equid figurine from Tell Brak (TB reg. no. 3070). After Oates et al. 2001: 289, fig. 311. Courtesy of Augusta McMahon / Tell Brak Project.

Fig. 2. Terracotta equid figurine from Tell Mozan (A10.415). Courtesy of The International Institute for Mesopotamian Area Studies.

Fig 3. Terracotta equid figurine from Tell Arbid. Courtesy Maciej Makowski / Institute of Mediterranean and Oriental Cultures, Polish Academy of Sciences.

Fig. 4. Inlay from Mari. Re-drawn after Parrot 1956: pl. LVIIb.

Fig. 5. Inlay from Mari. Re-drawn after Parrot 1967: pl. LXV no. 2468.

Fig. 6. Head of terracotta equid figurine from Tell Mozan (J1q377.1). Courtesy of The International Institute for Mesopotamian Area Studies.

Fig. 7. Terracotta equid figurine from Tell Brak (TB reg. no. 10076). After Oates et al. 2001: 595, no. 55. Courtesy of Augusta McMahon / Tell Brak Project.

Fig. 8. The Standard of Ur. 'Peace' side (top), and 'War' side (bottom) (BM 121201). Courtesy of The British Museum.

Fig. 9. Donkey showing lines of neck and head in relation to body and the ground. The Donkey Sanctuary, Sidmouth. Photo by Laerke Recht.

Fig. 10. Plaque with equid team from Nippur. Re-drawn after Zarins 2014: fig. 2.63.

Fig. 11. Egyptian wall painting from the Tomb of Nebamun, 18th Dynasty (BM EA37982).

Courtesy of The British Museum.

Fig. 12. Drawing of decoration on gold vessel from Ugarit (selection). Re-drawn after Schaeffer 1949: 10. 


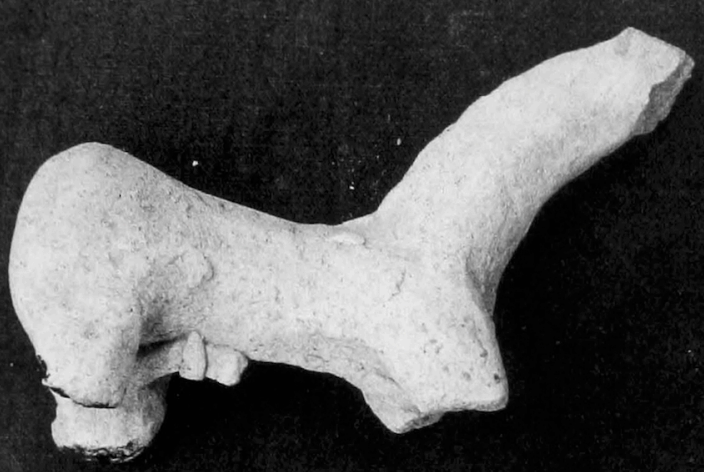

0

$5 \mathrm{~cm}$

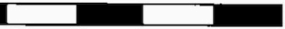




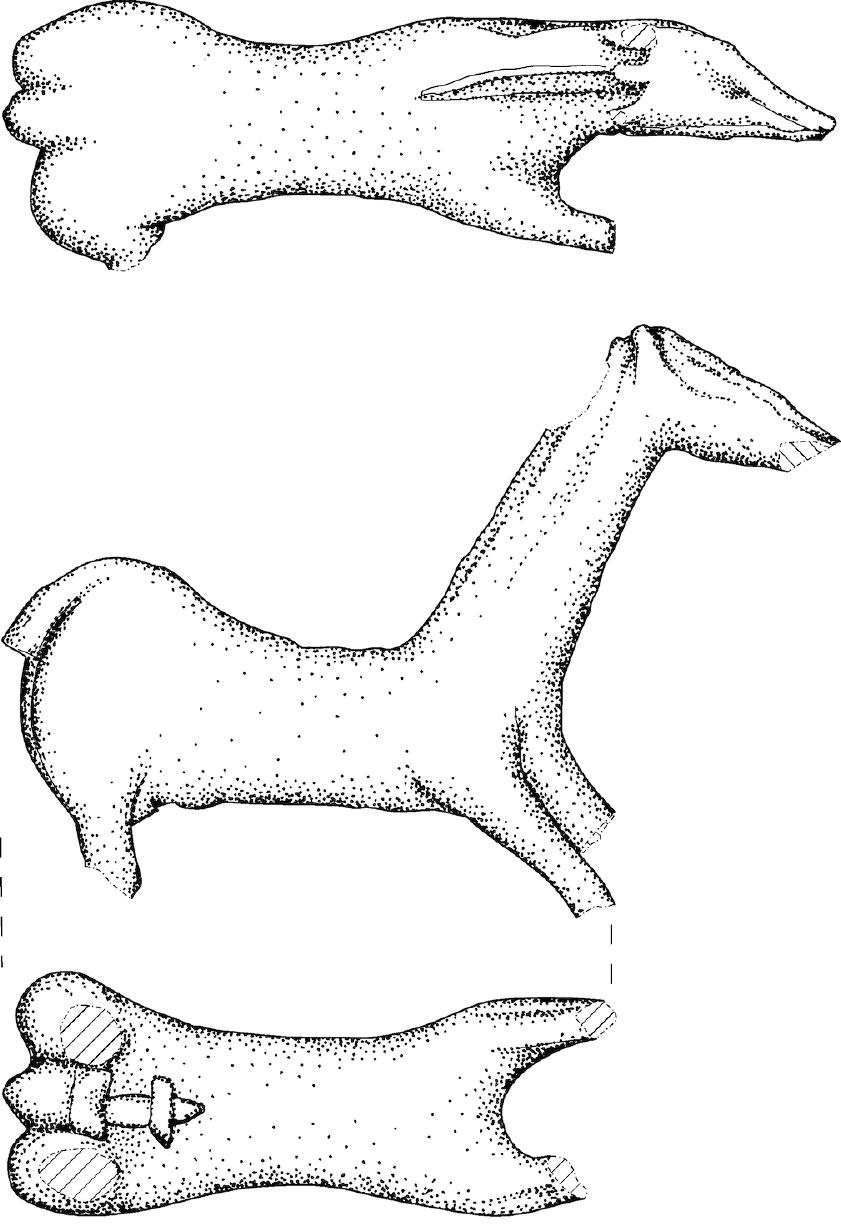


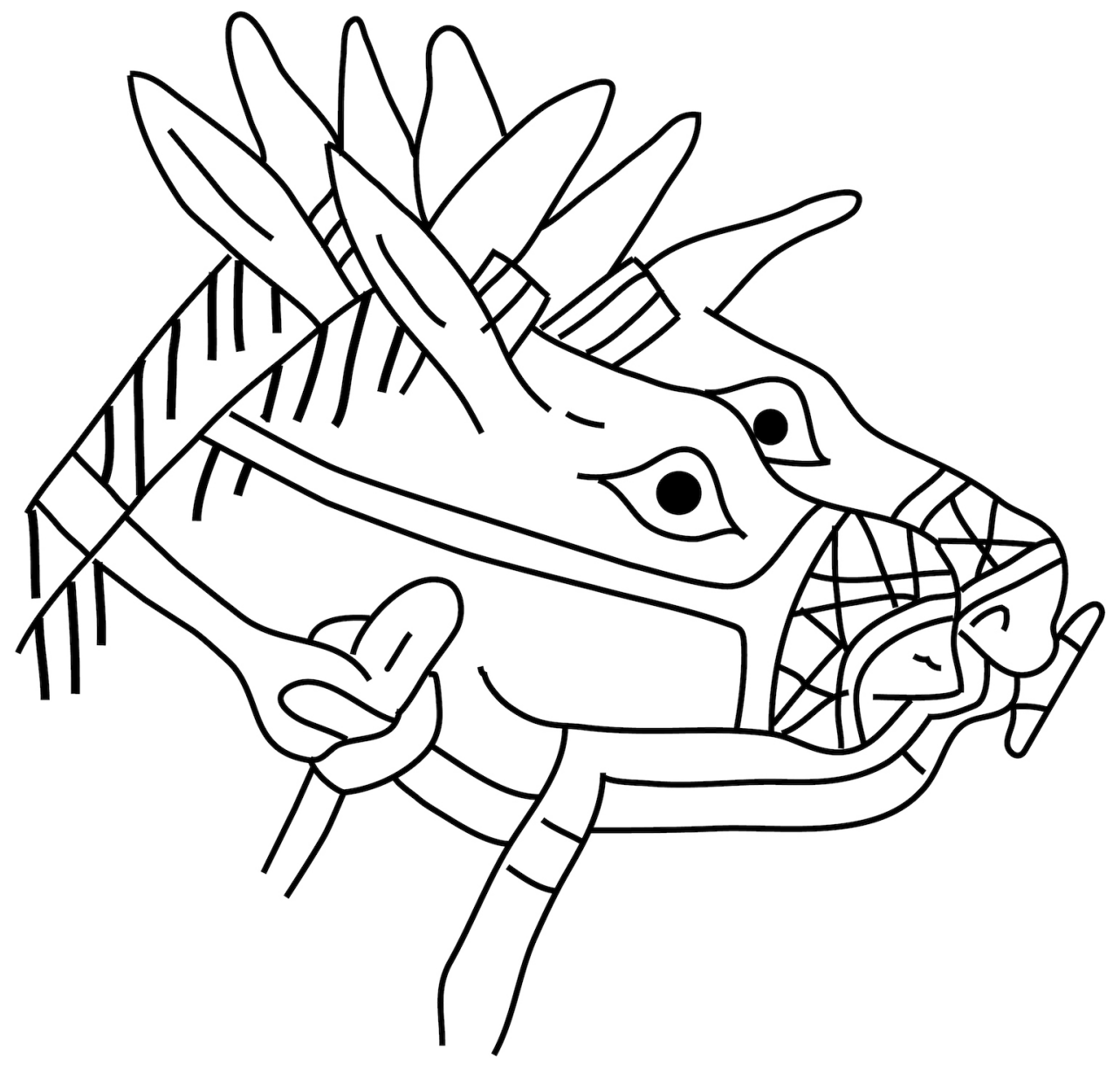




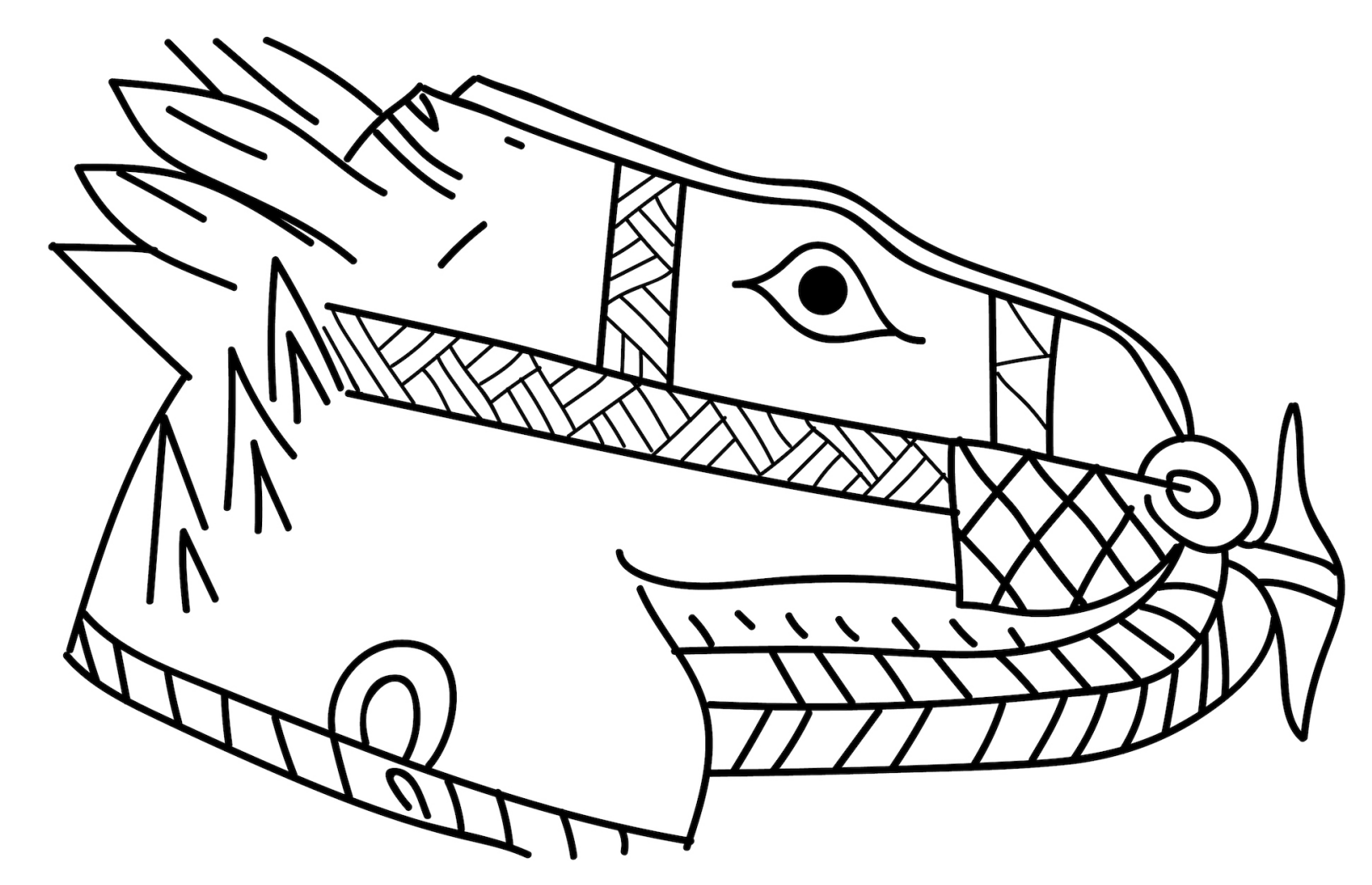




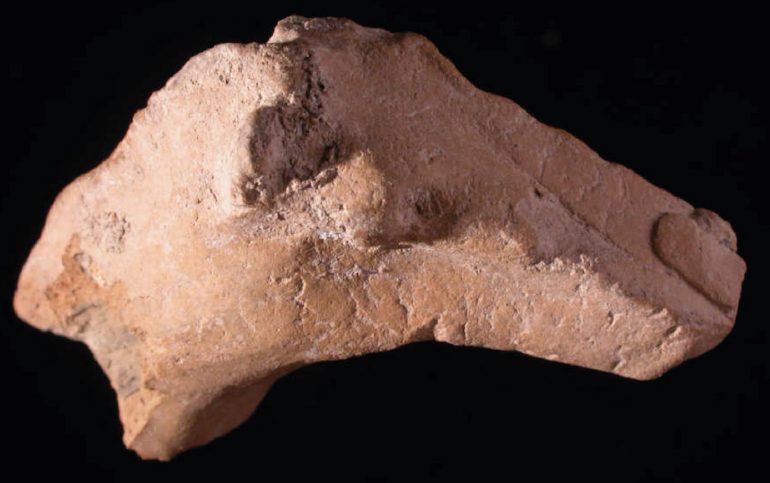




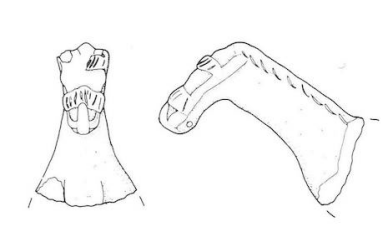




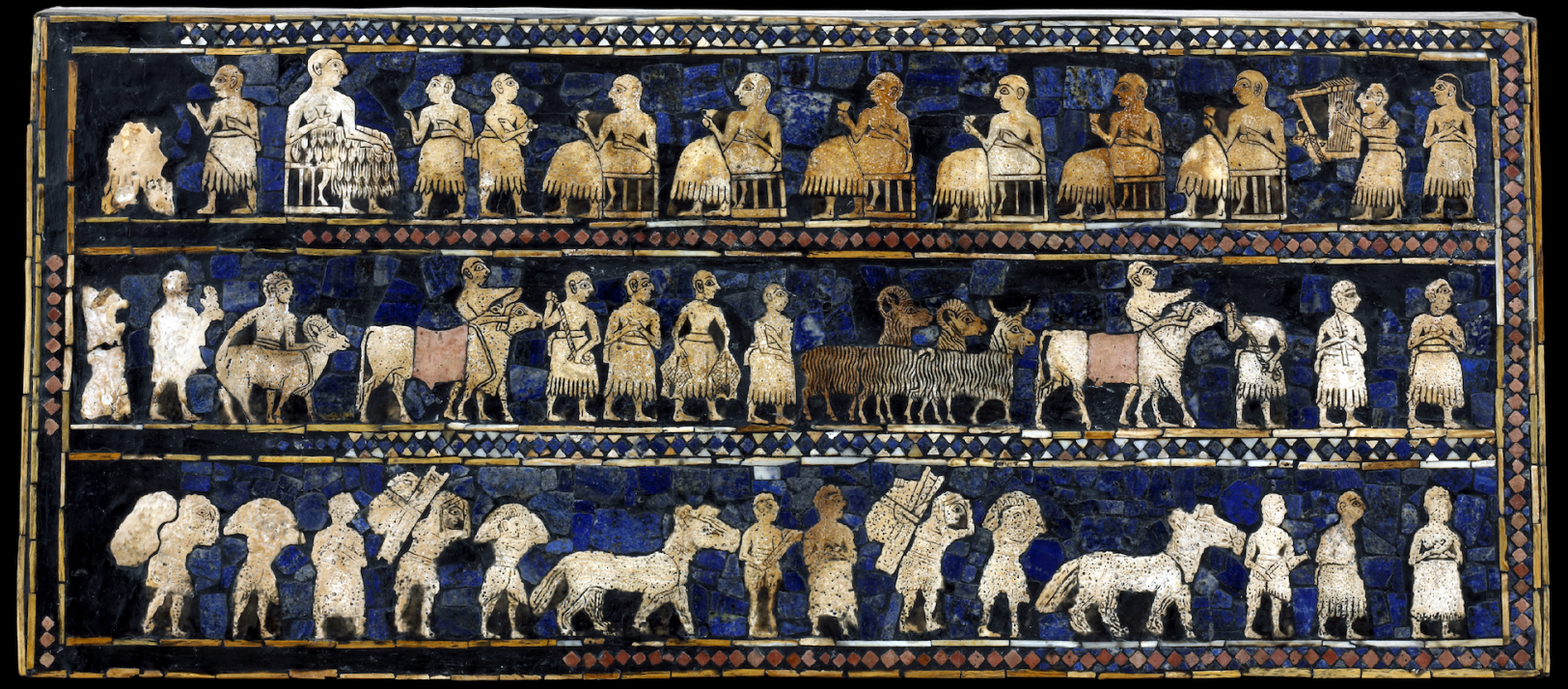




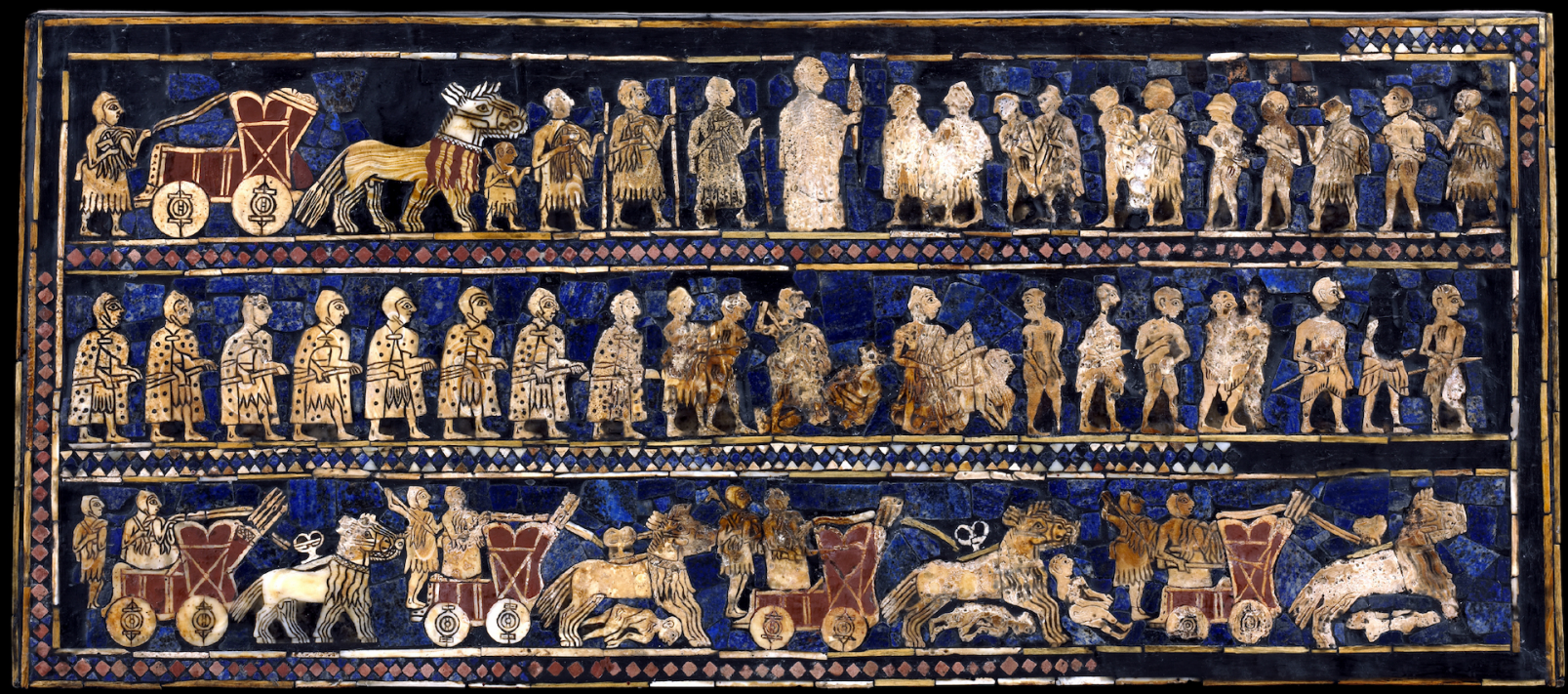




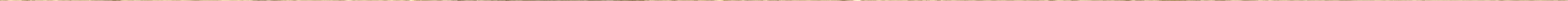




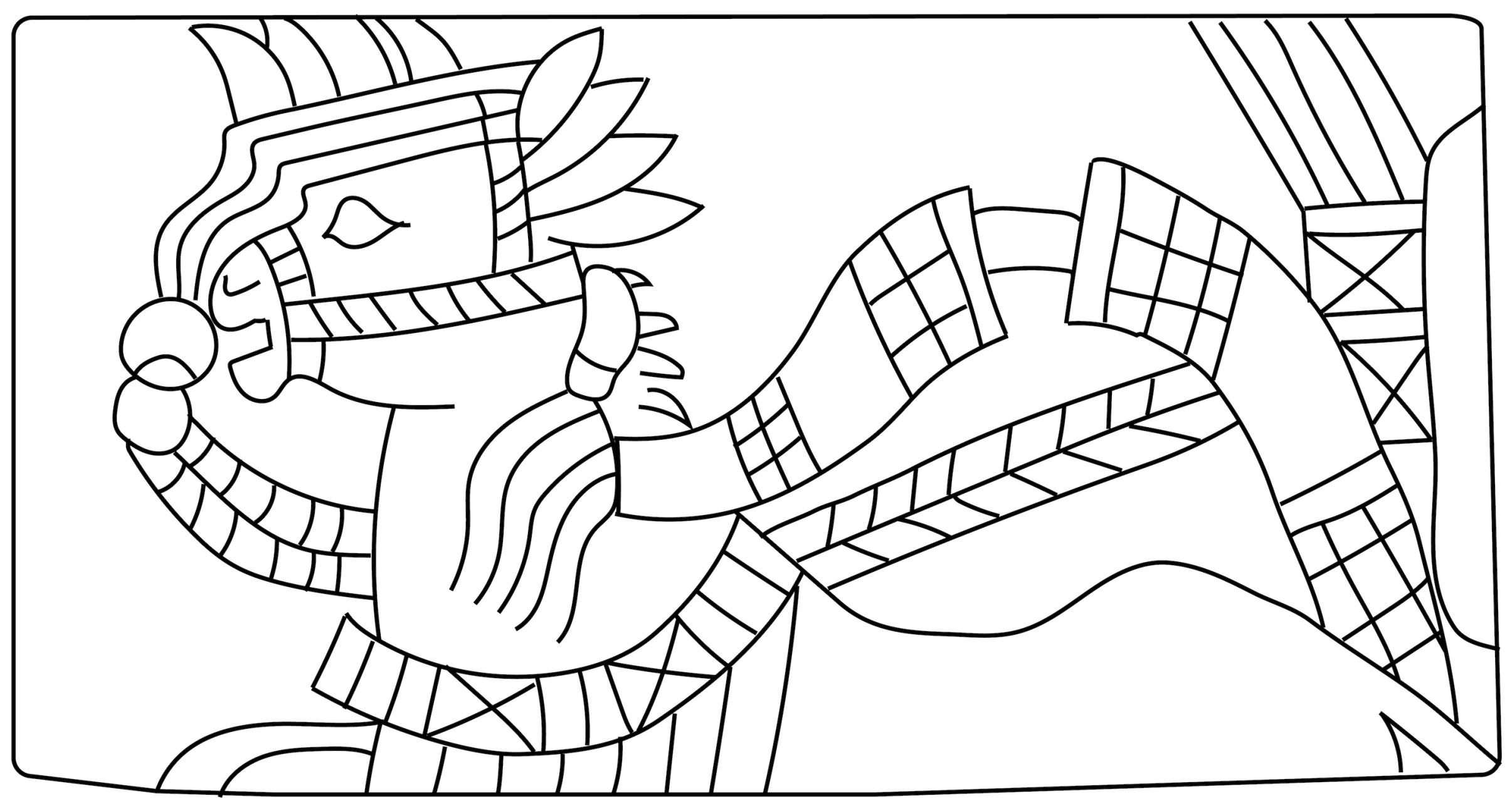




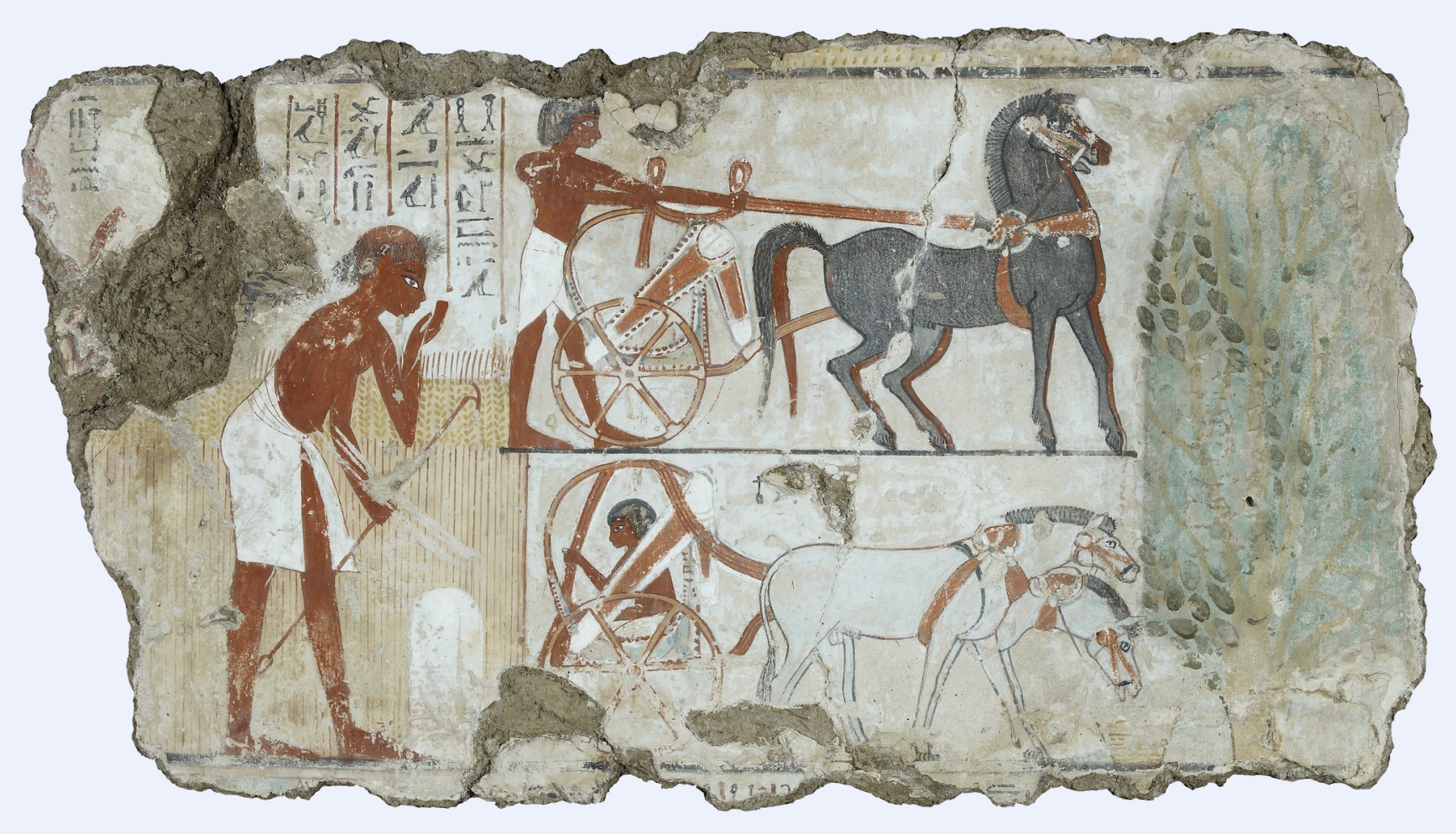



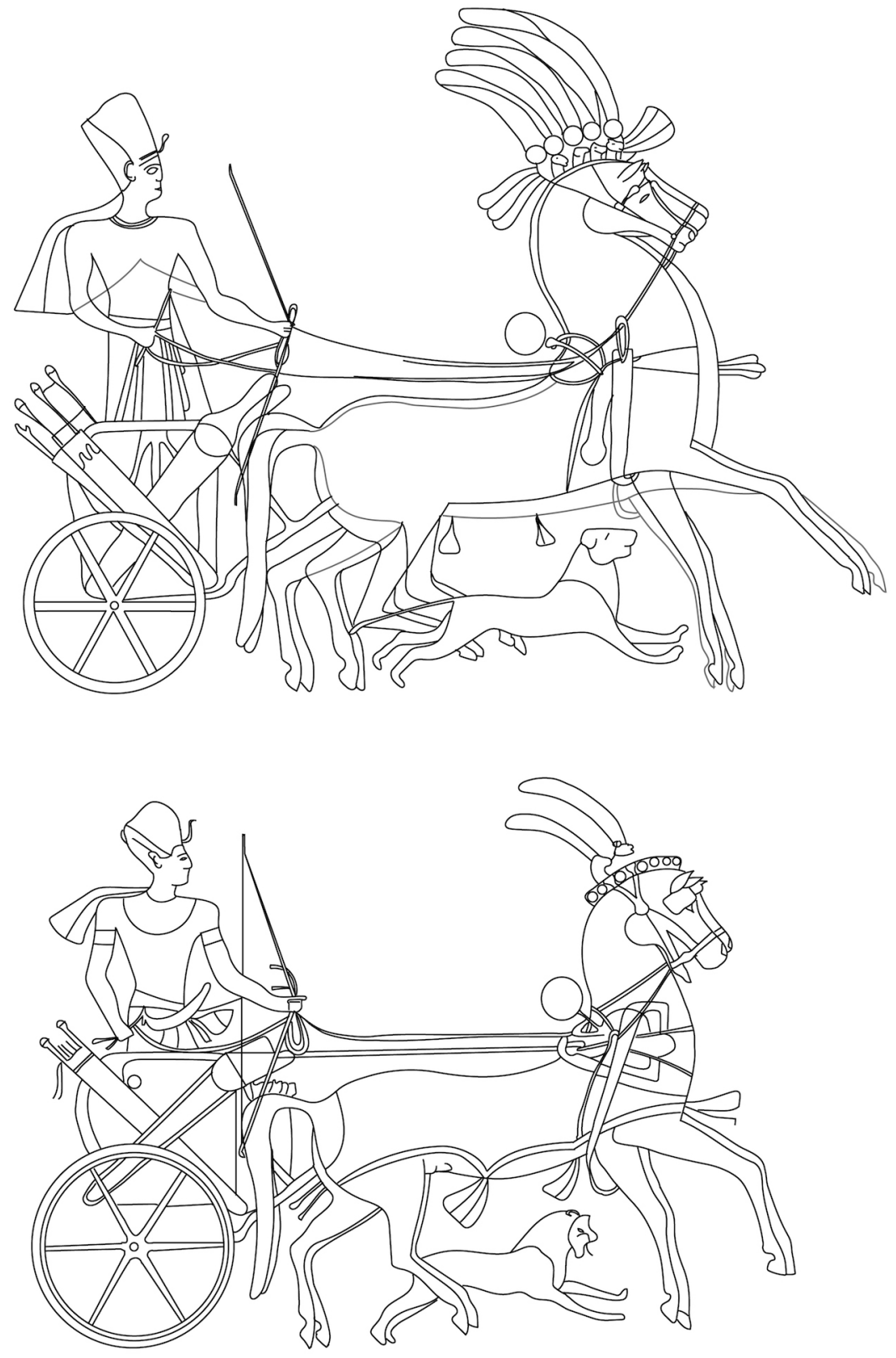